\title{
Da seleção de candidatos ao recrutamento político no Brasil (1986-2014)
}

\author{
Bruno Fernando da Silva ${ }^{1}$
}

CODATO, Adriano; COSTA, Luiz Domingos; MASSIMO, Lucas (Eds.). Retratos da classe política brasileira. Estudo de Ciência Política. Saarbrücken: Novas Edições Acadêmicas, 2015. 333 p.

Retratos da classe política brasileira é uma coletânea de artigos de Ciência Política que reúne trabalhos que contemplam desde a seleção de candidatos e as motivações para o ingresso na política até o recrutamento político e os determinantes do sucesso eleitoral. A obra, dividida em dez capítulos, fornece uma grande contribuição para o campo de estudo de elites políticas, enfatizando, sobretudo, a importância de variáveis políticas e sociais para compreender fenômenos políticos. Além disso, os trabalhos contidos no livro promovem um intenso debate com estudos nacionais e internacionais da área, trazendo importantes reflexões teóricas e metodológicas para se tentar compreender os processos em andamento na política nacional. 0 livro, portanto, partilha do mesmo interesse recente demonstrado por pesquisas como de Rodrigues (2002 e 2006), Marenco dos Santos e Serna (2007), Perissinotto et al (2007), Braga (2008), Perissinotto e Miríade (2009), Coradini (2012), Marenco dos Santos (2013) e outros tantos. Para esses autores, a classe política brasileira é um fenômeno relevante a ser explicado e, para isso, deve-se investigar desde aspectos sociais de candidatos e eleitosaté a importância de variáveis demográficas, partidárias e ideológicas.

Em seu primeiro capítulo, o livro apresenta uma discussão metodológica sobre a codificação de ocupações prévias de candidatos em estudos de elites políticas. Codato, Costa e Massimo dialogam com os critérios adotados pela literatura para definir e mensurar as profissões prévias à política que propiciam melhores condições de acesso à carreira parlamentar. 0 objetivo, com isto, é propor uma nova classificação de ocupações que considere apredisposição das profissões para a atividade política. Para isto, os autores recorrem a Weber (1982) e Norris e Lovenduski (1997) para estabelecer critérios que possam ser

\footnotetext{
${ }^{1}$ Mestre em Ciência Política pela Universidade Federal do Paraná (UFPR). E-mail: b.fernando91@gmail.com.
} 
empregados na verificação de tal disposição (p. 36). Assim, Codato, Costa e Massimo propõemum indicador que localiza a propensão das ocupações para a atividade política em três categorias: alta, média e baixa. 0 indicador considera a flexibilidade das carreiras (autonomia e disponibilidade temporal), o status social que ela confere aos sujeitos e a afinidade que a profissão tem com a política.

O grande mérito do capítulo escrito por Codato, Costa e Massimo está em propor um largo diálogo com a literatura, problematizando as formas com que trabalhos recentes classificaram ocupações e o impacto disso para a replicação das pesquisas. Há, entretanto, uma falha ao comunicar os procedimentos adotados para a categorização das profissões. Isto porque, os autores não detalham e nem sumarizam a disposição das ocupações entre os diferentes níveis de propensão à política, o que dificulta a replicação da classificação em outros estudos - ironicamente, está é uma das críticas dos autores a trabalhos recentes. Por fim, alguns problemas que são postos pelos próprios autores não são problematizados no âmbito da aplicação do índice por eles proposto. Notadamente, estamos nos referindo aqui às implicações no uso de ocupações autodeclaradas (DOGAN, 1961).

0 perfil social e a carreira dos senadores brasileiros eleitos entre 1986 e 2010 é o tema do segundo capítulo, escrito por Costa e Codato. 0 trabalho tem como objetivo comparar as proposições feitas por pesquisas anteriores em relação ao recrutamento político e a composição social da Câmara dos Deputados, com os dados sobre o Senado Federal brasileiro. Assim, os autores mobilizam variáveis como a ocupação prévia dos senadores, a formação universitária, os cargos políticos ocupados pelos parlamentares e o tempo de carreira política. Em geral, Costa e Codato apontam para uma profissionalização das carreiras de senadores, com baixo número de parlamentares da câmara alta eleitos sem ter passado por cargos legislativos (19\%) e aumento progressivo no tempo médio de carreira política dos senadores. A pesquisa mobiliza um elevado volume de informações sobre a composição social de senadores e dos partidos dentro do senado, assim como da trajetória política dos eleitos. Conforme proposto, dialoga permanentemente com a literatura sobre o tema. Todavia, carece de uma sistematização dos resultados e de uma explicação final dos autores sobre o que seus achados indicam, que é dificultada muito em decorrência da quantidade excessiva de variáveis empregadas na análise.

O terceiro capítulo, por sua vez, mapeia a carreira política dos senadores empresários entre os anos de 1986 e 2010. Costa, Costa e Nunes mostram que estes políticos estão alocados, sobretudo, em 
partidos de centro (PMDB e PSDB), possuem ensino superior completo, debutam na carreira política em idade média semelhante às demais profissões e chegam ao senado após um período médio de carreira próximo aos demais também. Os autores argumentam que a fórmula eleitoral majoritária e a profissionalização do recrutamento político no senado podem explicar as semelhanças entre as carreiras de empresários e outros profissionais. Neste sentido, as vantagens econômicas e sociais dos empresários produzem menos efeitos sobre o seu sucesso eleitoral em disputais mais institucionalizadas, como é o caso do senado (p. 102).

Quais são as principais distinções políticas, sociais e demográficas de eleitos e derrotados à Câmara dos Deputados nas eleições de 1998 a 2006? Esta é a pergunta que Perissinotto e Bolognesi buscam responder no quarto capítulo do livro. De saída, os autores demonstram que algumas profissões, como comerciantes e funcionários públicos, estão proporcionalmente mais representadas entre derrotados do que eleitos. Já legisladores, advogados, médicos, engenheiros e economistas, por sua vez, apresentam maior percentual de eleitos do que não-eleitos. São encontradas também diferenças por sexo e escolaridade, com candidatos homens e com ensino superior sobrerrepresentados entre vitoriosos em relação aos demais - contudo, estas variáveis têm baixo poder explicativo para o sucesso eleitoral. Os autores analisam também o impacto de todas essas variáveis para o desempenho eleitoral com base na ideologia dos partidos. Apesar das diferenças internas em relação à importância que cada ocupação tem para o sucesso eleitoral na direita, esquerda e centro, ser político profissional é a variável com maior impacto sobre a vitória dos candidatos, independente da ideologia do partido. Com isto, Perissinotto e Bolognesi sugerem que tal fato seja efeito de uma crescente institucionalização do recrutamento para a Câmara dos Deputados, que exige cada vez mais uma maior profissionalização política dos concorrentes. Sem dúvida, o trabalho dos autores colabora para o avanço das pesquisas de elites, assim como dos determinantes dos resultados eleitorais. A principal falha, contudo, parece ser com a apresentação dos dados, que é feita de maneira pouco organizada, dificultando a compreensão e a interpretação dos resultados por parte dos leitores. A simples aposta em representações gráficas e algumas agregações de categorias poderiam tornar a leitura mais agradável e fluída.

A institucionalização do recrutamento político é o fio condutor das discussões realizadas no quinto capítulo, de autoria de Cervi et al. Assim como todos os capítulos que seguem (com exceção do oitavo), o enfoque dos autores é a Câmara dos Deputados. Para testar a hipótese 
de um campo político mais autonomizado e de uma classe política mais profissionalizada, o trabalho mobiliza variáveis como ocupação, partido político e financiamento eleitoral. A conclusão que se chega é de que candidatos à reeleição, pertencentes a partidos grandes e com alto volume de financiamento têm melhores chances de sucesso nas eleições. De outro lado, indivíduos que tentam progressões laterais em suas carreiras políticas logram menores chances de êxito. Por óbvio, nota-se um descolamento do campo político em relação aos demais e maior profissionalização dos parlamentares. Isto é reafirmado pelo elevado volume de recursos financeiros em campanhas de candidatos à reeleição e pelo fato destes estarem alocados, sobretudo, em grandes partidos. Os autores, porém, pouco discutem estes processos - de autonomia e profissionalização- de maneira sistemática, ainda que este seja o tema de interesse deles.

A questão da representação social entre candidatos à Câmara volta mais uma vez a discussão no sexto capítulo, com Costa, Bolognesi e Codato, mas agora acrescida da representação de gênero. Desta vez, a análise recai sobre os principais partidos de esquerda (PT e PDT), direita (DEM e PP) e centro (PSDB e PMDB) na eleição de 2006 e as estratégias por eles adotadas no que concerne às representações sociais e de gênero. Como já havia mostrado Rodrigues (2002 e 2006), entre os eleitos, predominam na direita os empresários, enquanto que os professores são maioria em partidos de esquerda. Há também um número mais elevado de mulheres eleitas e que se declaram políticas na esquerda do que em outros partidos. Outra variável empregada pelos autores é o potencial eleitoral dos candidatos (baseado em Rahat e Hazam, 2001 apud Codato, Costa e Massimo, 2015). Eles concluem que partidos de esquerda são mais abertos a candidatos inviáveis e que uma das estratégias destes partidos é lançar o maior número de competidores. Já em partidos de direita, menos indivíduos concorrem à eleição, mas com um elevado número de supercandidatos.

Este é mais um capítulo que carece de uma atenção maior em relação à sistematização dos resultados. São apresentados muitos dados, mas pouco se discute o que eles significam, sobretudo, quando tomados em conjunto. A questão da representação de gênero, que aparentemente era central, também acaba sendo pouco explorada, principalmente sobre os aspectos que explicam a baixa presença das mulheres no parlamento. Por fim, as variáveis sócio-políticas, que seriam empregadas para compreender a participação feminina, acabam sendo utilizadas em maior parte para explicar as estratégias eleitorais dos partidos. 
O sétimo capítulo do livro, de autoria de Costa, Bolognesi e Codato, traz um interessante estudo exploratório sobre o lugar dos trabalhadores nos partidos brasileiros. Mostra-se que o aumento de $41 \%$ no número de candidatos trabalhadores manuais ou autônomos entre 1998 e 2014 não é acompanhado de um maior espaço para estes profissionais em partidos grandes, independente do espectro ideológico destes partidos. São, portanto, os partidos pequenos e/ou fisiológicos que têm propiciado aos trabalhadores condições de concorrer à Câmara. Os motivos para isto, segundo os autores, é de que os grandes partidos estão se profissionalizando, o que reduz o espaço para candidatos inexperientes ou que não são ligados à burocracia dos partidos. A pesquisa também analisa a presença de trabalhadores nas listas do PT e apresenta explicações para o número cada vez menor destes profissionais concorrendo à Câmara dos Deputados.

Investigar as variáveis que estiveram mais relacionadas com o sucesso eleitoral de candidatos a prefeito, em todo o Brasil, nas eleições de 2012, é o objetivo de Codato, Cervi e Perissinotto no oitavo capítulo. Finalmente, o livro deixa de lado as discussões sobre candidatos ao legislativo federal e aborda a esfera municipal. Ao todo, os autores empregaram doze variáveis explicativas binárias em um modelo de regressão logística em que a variável a ser explicada é o resultado eleitoral (eleito ou não-eleito). Eles concluem que variáveis políticas, como concorrer à reeleição e por um partido coligado, impactaram mais positivamente sobre a vitória dos candidatos do que variáveis econômicas (patrimônio e financiamento) e sociais (sexo, idade, escolaridade e ocupação). Todavia, algumas decisões metodológicas dos autores são questionáveis e podem ter afetado os resultados. Uma delas é decorrente da escolha em trabalhar apenas com variáveis independentes dicotômicas, mesmo quando isto acarreta em uma perda grande de informações - como é, notadamente, o caso do financiamento de campanhas, patrimônio e idade. Outra decisão dos autores foi de trabalhar com a média de financiamento e patrimônio para diferenciar os candidatos. Como os próprios autores admitem, há uma grande heterogeneidade de valores ao se trabalhar com estas variáveis (p. 212), portanto, mesmo que isto seja ponderado pelo tamanho dos municípios e região, é provável que a média não seja o melhor parâmetro para estimar receita e patrimônio. Por fim, os autores abdicam da oportunidade de comparar os achados da pesquisa com trabalhos sobre o sucesso eleitoral em disputas legislativas. Assim, não é possível ao leitor concluir se existem diferenças no recrutamento político para o congresso e em disputas locais.

Como a institucionalização dos partidos afeta a seleção de candidatos? 0 penúltimo capítulo, de Bruno Bolognesi, analisa de 
maneira muito convincente estes processos com base em 120 candidatos dos quatro principais partidos brasileiros (PT, PMDB, PSDB e DEM). Tratando inicialmente da institucionalização partidária², os dados apontam para uma maior organização interna e eleitoral dentro do PT, seguido de PSDB e PMDB com resultados muito próximos e DEM por último. Já ao analisar a seleção de candidatos para a Câmara dos Deputados, o autor observa um maior poder nas mãos de líderes no próprio DEM, com a organização do partido tendo um papel muito pequeno na escolha dos competidores. No PT, contrariamente, os líderes desempenham um papel menor na elaboração das listas, que fica a cargo, sobretudo, de delegados, mas também dos filiados ao partido. Os partidos com posição intermediária de institucionalização (PSDB e PMDB) diferem-se não somente nos aspectos privilegiados dentro da organização como na forma de seleção. O PSBD, com melhores resultados de institucionalização na arena eleitoral do que em organização, diversifica os atores que montam as listas de candidatos: filiados, delegados e líderes têm participação no processo. Por fim, o PMDB, que conta com maior organização interna do que foco sobre a arena eleitoral, seleciona seus candidatos pelo voto de filiados ou pela escolha de líderes - contudo, estes são mais determinantes (p. 266). Neste sentido, Bolognesi conclui que o grau de institucionalização dos partidos é uma variávelimportante para compreender o processo de seleção de candidatos.

No décimo e último capítulo, Bolognesi e Medeiros fazem uma interessante analise sobre as motivações para a entrada na política e a socialização inicial na política de 120 candidatos a deputado federal pelo PT, PSDB, PMDB e DEM, nos estados de São Paulo, Paraná, Rio Grande do Sul, Sergipe e Pará. Os autores ponderam as respostas dos entrevistados pelo partido ao qual pertencem, formação universitária e ocupação. Em geral, observa-se que os candidatos da pesquisa se interessaram por política inicialmente no ambiente familiar e em movimentos estudantis de ensino médio e universitário. Além disso, o ambiente de interesse inicial pela política é importante para entender as razões dos candidatos em se lançarem a ela. 0 trabalho segue com análises sobre o tempo dedicado por cada um dos entrevistados para a política e como isso foi afetado pelas exigências partidárias de profissionalização e burocratização. Os autores concluem que o momento de interesse inicial pela política, a área de formação e os partidos políticos são variáveis importantes para compreender a socialização e a profissionalização política dos entrevistados.

\footnotetext{
2 Segundo o autor, "institucionalização deve ser entendida como capacidade da instituição em criar rotina e internalizar valores a fim de aumentar a previsibilidade da ação dos atores em médio prazo" (p. 241).
} 
Como se observa, mais do que uma vertente teórica em comum a Sociologia Política - os capítulos partilham coesão com a proposta inicial da obra. Além disso, os trabalhos são complementares uns aos outros e fazem jus ao título do livro, fornecendo um retrato da elite política brasileira. Contudo, a recorrência a alguns temas, em especial as ocupações de candidatos e eleitos ou ainda a profissionalização do recrutamento político, tornam algumas teses excessivamente repetitivas. Isto porque, do primeiro ao sétimo capítulo, a ocupação e a profissionalização são aspectos fundamentais para a explicação dos fenômenos observados. Algo que poderia ter sido feito é a exploração dessas variáveis em outros níveis, afinal, enfatiza-se demasiadamente as elites políticas em âmbito federal enquanto apenas uma das pesquisas recorre às disputas municipais. Pouco se sabe, por exemplo, qual é o perfil político e social de candidatos em eleições às câmaras municipais e às assembleis legislativas brasileiras e se há convergência no recrutamento político destas disputas em comparação com eleições nacionais. Certamente, sob posse dessas informações, a obra seria ainda mais abrangente e forneceria uma imagem ainda melhor da elite política no Brasil.

\section{Referências}

BRAGA, Maria S. S. Organizações partidárias e seleção de candidatos no estado de São Paulo. Opinião Pública [online], v. 14, n. 2, p. 454-485, 2008.

CORADINI, Odaci L. Categorias sócio-profissionais, titulação escolar e disputas eleitorais. Rev. Sociologia Política, Curitiba, v. 20, n. 41, p. 109122, fev. 2012.

DOGAN, M. Political Ascent in a Class Society: French Deputies, 1870-1958. In: Dwaine, M. Political Decision-Makers. New York: FreePress of Glencoe, 1961.

MARENCO DOS SANTOS, André; SERNA, Miguel. Por que carreiras políticas na esquerda e na direita não são iguais? Recrutamento legislativo em Brasil, Chile e Uruguai. Revista Brasileira de Ciências Sociais, v. 22, n. 64, p. 93113, jun. 2007.

MARENCO DOS SANTOS, André. Os Eleitos: representação e carreiras políticas em democracias. Rio Grande do Sul: Editora UFRGS, 2013.

NORRIS, P. \& LOVENDUSKI, J. United Kingdom. In: Norris, P. Passages to Power: Legislative Recruitment in Advanced Democracies.Cambridge: Cambridge University Press, 1997.

PERISSINOTTO, Renato M. CODATO, Adriano; FUKS, Mario; BRAGA, Sérgio. Quem Governa? Um estudo das elites políticas do Paraná. Curitiba: Editora UFPR, 2007 
PERISSINOTTO, Renato M.; MIRÍADE, Angel. Caminhos para o parlamento: candidatos e eleitos nas eleições para deputado federal em 2006. Dados, Rio de Janeiro, v. 52, n. 2, p. 301-333, 2009.

RODRIGUES, Leôncio M. Partidos, ideologia e composição social: um estudo das bancadas partidárias na Câmara dos Deputados. São Paulo: Edusp, 2002.

. Mudanças na classe política brasileira. São Paulo: Publi Folha, 2006.

WEBER, Max. A política como vocação. In: GERTH, H. H.; MILLS, C. W. Max Weber. Ensaios de sociologia. 5. ed. Rio de Janeiro: Livros Técnicos e Científicos, 1982.

Recebido em 01 de março de 2016 Aprovado em 28 de março de 2016 